\title{
All-Male Panels and Gender Diversity of Issue Panels and Plenary Sessions at ISPOR Europe
}

\author{
Jacoline C. Bouvy ${ }^{1}\left[\right.$ [ $\cdot$ Michelle Mujoomdar ${ }^{2}$
}

Published online: 22 July 2019

(c) The Author(s) 2019

Despite making up half of the world's population, women are still underrepresented in many fields of science, business and politics. At conferences, the all-male panel ('manel') is a well-known and increasingly criticised phenomenon. Furthermore, there is growing awareness of the need to ensure diversity among speakers at international conferences. Especially in panel sessions at scientific conferences that aim to debate issues from a variety of perspectives, it is crucial that these perspectives extend beyond those of white men.

In our own personal experience, the health economics and outcomes research (HEOR) field is not particularly male-dominated. In our own organisations and in scholarly work, we encounter many women who make important contributions to the field. Yet, in recent years we have observed that speaker diversity at many conferences, workshops and symposia in the HEOR field remains disappointing. In order to assess whether our own observations held any truth, we assessed the gender distribution of speakers at the International Society for Pharmacoeconomics and Outcomes Research (ISPOR) Europe conferences issue panels and plenary sessions. We selected ISPOR conferences as ISPOR is "the leading professional society for health economics and outcomes research globally" [1] and the annual European meeting is its largest meeting, with almost 5000 attendees in 2017 [2] making it, to the best of our knowledge, the largest annual scientific conference in HEOR worldwide.

Electronic supplementary material The online version of this article (https://doi.org/10.1007/s41669-019-0153-0) contains supplementary material, which is available to authorized users.

Jacoline C. Bouvy

Jacoline.bouvy@nice.org.uk

1 Science Policy and Research Programme, National Institute for Health and Care Excellence (NICE), 10 Spring Gardens, London SW1A 2BU, UK

2 Evidence Standards, Canadian Agency for Drugs and Technologies in Health (CADTH), Ottawa, ON, Canada
We included ISPOR Europe conferences of the last 3 years (2018 Barcelona; 2017 Glasgow; 2016 Vienna) in our sample. We did not include more years in our dataset as the programmes of conferences that took place earlier than 2016 were no longer accessible through the ISPOR website. For each conference, we used the programme to identify the list of speakers for each issue panel (between 20 and 30 in total per conference) and for all plenary sessions (three per conference). We included issue panels as these are meant to debate views on controversial topics. The submission instructions for issue panels are that they are "designed to stimulate real debate on new or controversial topics in health economics and outcomes research" and that "each panelist is expected to provide a different perspective on the issue" [3]. In addition, in order to be able to submit an abstract for an issue panel, the moderator of the issue panel must have invited the experts to participate in the panel. The ability to participate in issue panels, therefore, requires a panellist to be recognised by their peers as an expert on the issue panel's topic and to be invited to contribute to an abstract for submission to the conference.

We assumed people listed in the conference programme with names commonly used by males to identify as male and people listed with names commonly used by females to identify as female. When we encountered a name where gender was not obvious (e.g. Kim, Robin) we used Google to assess the gender the person most likely identified as, for example through their LinkedIn profile page. Although some people will identify as neither male nor female, for the purposes of this study we were unable to be more specific. Both authors extracted all data independently. Inter-rater reliability was assessed and all divergences were solved through consensus. We used Microsoft Excel ${ }^{\circledR}$ to calculate the gender distributions for each year.

We found that, in total, $70 \%$ of speakers listed on issue panels and plenary sessions at ISPOR Europe conferences during 2016-2018 were males. In total, 346 people participated in 85 issue panels and plenary sessions at ISPOR 
Table 1 Male and female speakers and distribution of speakers on issue panels and plenary sessions at International Society for Pharmacoeconomics and Outcomes Research (ISPOR) Europe conferences in 2016, 2017 and 2018

Fig. 1 Distribution of speakers for all issue panels and plenary sessions at International Society for Pharmacoeconomics and Outcomes Research (ISPOR) Europe conferences in 2016, 2017 and 2018. Each bar represents an issue panel. The plenary sessions are indicated using black borders (three per conference)

\begin{tabular}{lccclll}
\hline Conference & Males $[n(\%)]$ & Females $[n(\%)]$ & \multicolumn{2}{l}{$\begin{array}{l}\text { Distribution of speakers on panels and plenary ses- } \\
\text { sions }[n(\%)]\end{array}$} \\
\cline { 5 - 7 } & & & Manels & $>50 \%$ males & $>50 \%$ females & $\begin{array}{l}\text { All- } \\
\text { female } \\
\text { panels }\end{array}$ \\
\hline Barcelona, 2018 & $87(70)$ & $37(30)$ & $9(30)$ & $19(63)$ & $3(10)$ & $1(3)$ \\
Glasgow, 2017 & $82(66)$ & $42(34)$ & $8(26)$ & $18(58)$ & $4(13)$ & $1(3)$ \\
Vienna, 2016 & $72(73)$ & $26(27)$ & $8(33)$ & $17(71)$ & $2(8)$ & $0(0)$ \\
Total & $241(70)$ & $105(30)$ & $25(29)$ & $54(64)$ & $9(11)$ & $2(2)$ \\
\hline
\end{tabular}

ISPOR Barcelona 2018

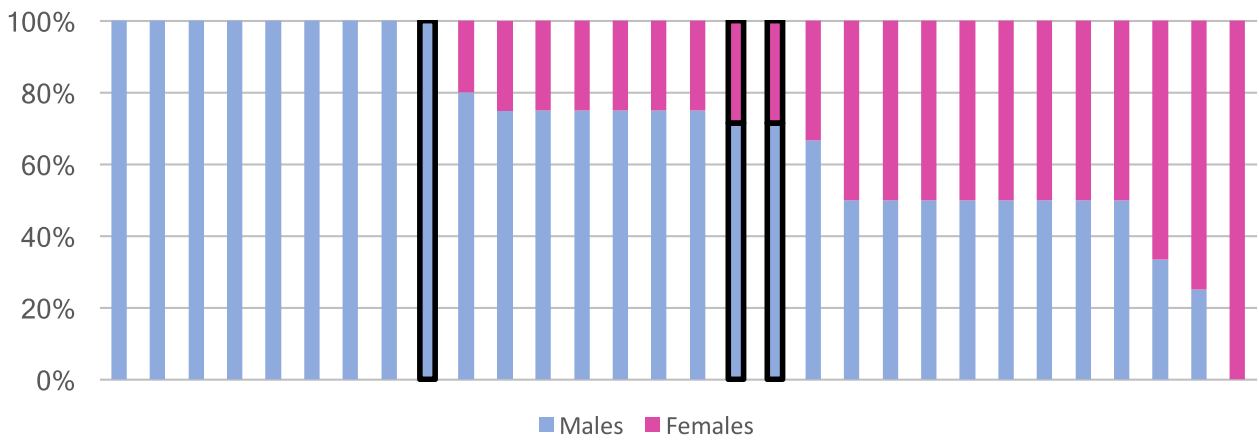

ISPOR Glasgow 2017

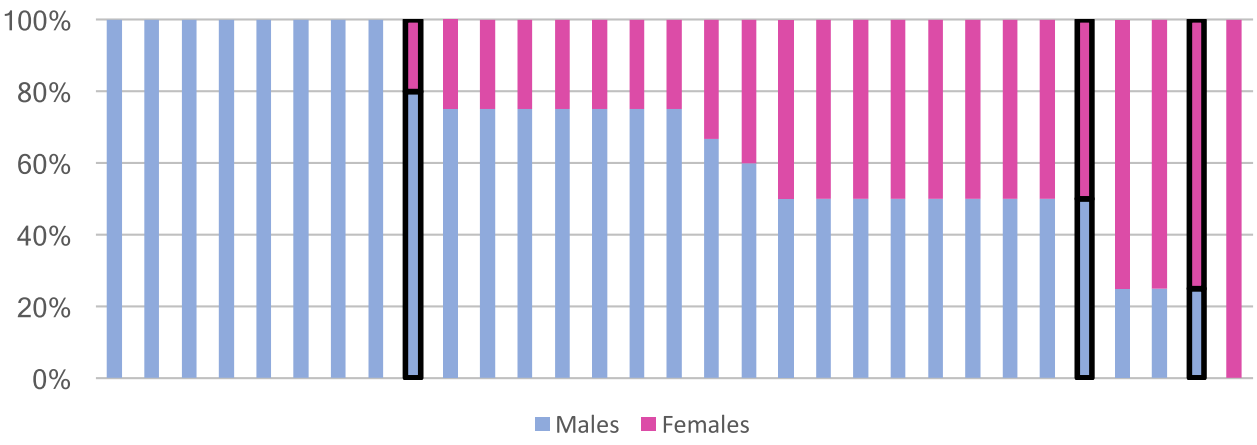

ISPOR Vienna 2016

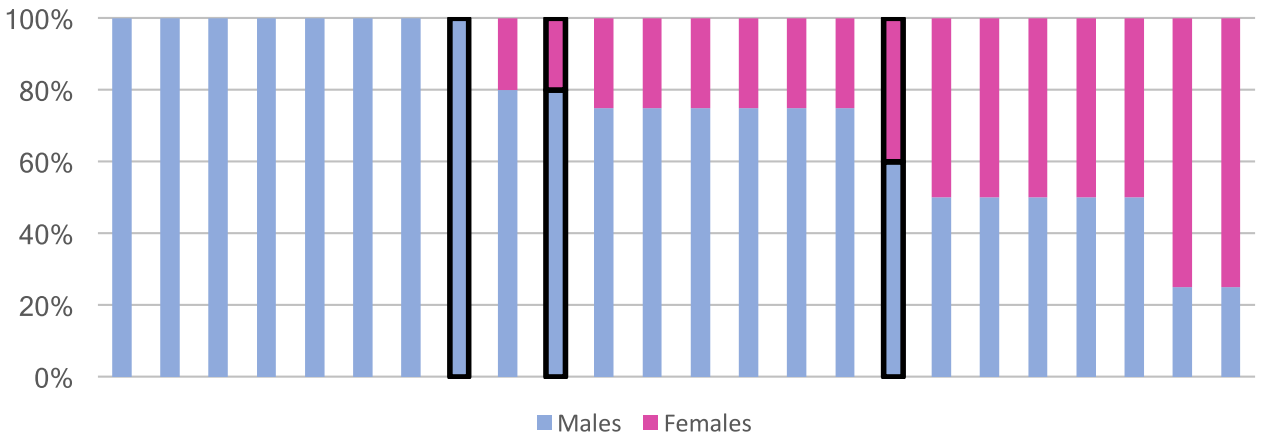

Europe conferences in 2016, 2017 and 2018 (Table 1). In $2016,73 \%$ speakers were male, with $66 \%$ male speakers in 2017 and $70 \%$ male speakers in 2018 .
Almost $30 \%$ of all panels at ISPOR Europe conferences were manels (29.4\% in 2016-2018) (Fig. 1, Table 1). Furthermore, issue panels and plenary sessions were male-dominated even if they were not a manel: $64 \%$ of all panels at the 
three conferences had a majority of male speakers $(>50 \%)$. Only $11 \%$ of the panels and plenary sessions had mostly female speakers $(>50 \%)$, and $26 \%$ of panels and plenary sessions had an equal amount of male and female speakers.

Only $2 \%$ of all panels (two panels of 85 in total) were all-female. Although we did not have access to the gender distribution of ISPOR members, in our experience HEOR is not a particularly male-dominated field, illustrated by the fact that eight of the 12 current members of the ISPOR Board of Directors are women. We highly doubt that our results can be explained solely by a lack of availability of sufficient female HEOR experts to participate in issue panels and plenary sessions.

The 'gender role hypothesis' assumes that the lower the number of women in a group, the less women participate in and influence its discussions and decision-making [4]. Reasons for this effect include that simply being a numerical minority in the group will lower the status and, subsequently, the authority and participation of women in the group's discussions [4]. The literature also suggests that women tend to participate in discussions less than men in male-dominated groups due to gendered norms of interaction that vary with gender composition, and that women's participation, and influence, increases as their proportion increases [4]. Currently, $64 \%$ of panels at ISPOR Europe are male-dominated. This means that, apart from the existence of a barrier for women to even participate in issue panels (as $29 \%$ of them do not include women at all), the current gender composition of ISPOR Europe's issue panels and plenary sessions might continue to contribute to undermining women's authority and participation in HEOR, simply due to them often being a minority on a panel.

ISPOR could make a meaningful contribution to advancing women in HEOR - the aim of ISPOR's own Women in HEOR Initiative [5] - by no longer accepting abstract submissions for issue panels where there is not at least one female panellist, preferably in a non-moderator role, and by banning all-male plenary sessions. Given ISPOR's interest in advancing women in HEOR, banning manels would both improve the gender balance of speakers at ISPOR conferences and also send a clear signal that ISPOR is serious about its commitment to advance women's leadership in the field. Speaking opportunities at plenary sessions and as a panellist for an issue panel can be important to advance the career of a HEOR professional, and, thus, are important for men and women to establish themselves as experts on key HEOR issues.

We did not take moderator versus non-moderator roles on issue panels and during plenary sessions into account. However, there is evidence to suggest that women are more often assigned the role of moderator, rather than as a panellist, when being invited to participate in a panel [6]. We were also not able to study other types of diversity at ISPOR, such as representation of speakers from different countries or from ethnic minorities, as there is not a straightforward method to do so. Notwithstanding, we strongly believe steps to improve diversity should not be limited to improving gender balance. Making other diversity requirements for the representativeness of speakers would be easy to implement and should be considered in the process of abstract submission and review.

Not everyone will share our view that the high proportion of manels at ISPOR Europe conferences-or any conference-is a problem. We believe that any person in the HEOR field, regardless of their gender or ethnicity, deserves equal access to career opportunities such as participating as experts in panel discussions and plenary sessions. There is evidence to suggest that women in different fields of science, including economics, face considerable gender bias that could explain why men frequently submit abstracts for issue panels that do not include women. Recent Dutch and French studies found that in university courses, female instructors received lower scores than male instructors on teaching evaluations despite producing similar grades, and this effect was mainly driven by male students scoring female instructors lower than male instructors [7, 8]. Women were found to receive lower scores on grant applications in Canada, an effect that disappeared when only the quality of the application was reviewed, and not the principal investigator [9]. When staff at a US university were asked to review job applications for a laboratory manager position where the applications were randomly assigned male or female names, male applicants were rated as significantly more competent and hireable than identical female applicants [10]. Therefore, there is evidence to suggest that women, including women in HEOR, are less likely to be recognised as experts by their peers, which could explain why so few women end up on issue panels at ISPOR Europe.

The persistence of gender bias also means that policies that encourage but do not enforce female participation are unlikely to be effective in creating more balanced panels. Gender bias is largely unconscious; we suspect that the men who submit manel abstracts for ISPOR Europe might not just exclude women from their panels purely because they are women; they might hold beliefs that there are no female experts available, or that the female experts they do know do not have the same level of authority or eminence as male experts do. Furthermore, seniority could be seen as a proxy for expertise, and it is possible there are fewer senior female HEOR experts. We believe it is unlikely people will make different choices, as they are largely driven by unconscious bias, unless they are forced to make a different choice. Therefore, we believe a manel ban for ISPOR Europe (and other conferences) is needed to improve the gender balance of its panels and plenary sessions. 
There are several limitations to this study. First, we only included data for the last 3 years of ISPOR Europe conferences, as the programmes for earlier years were not available. We cannot exclude the possibility that gender distribution was much more favourable before 2016, but, if this were the case, the decrease in diversity among speakers in recent years would be slightly alarming and even more reason for considering implementing policy changes. In addition, all data were collected manually and it is possible that some names were misclassified or errors made. However, both authors extracted all data independently, initial inter-rater agreement was $94 \%$, and all identified divergences were solved through consensus. We did not extend our analysis to other, similar conferences in HEOR. Different conferences use different formats for their online programmes, which limits the ability to collect the data in the same way we did for this study. For example, if the conference programme does not list first and last names, but only uses initials, it is much more challenging to assess gender distribution.

Despite laudable efforts to support women's leadership in the HEOR field, ISPOR's biggest conference has severe underrepresentation of women on issue panels and plenary sessions. Implementing a manel ban, by making it a requirement that an abstract submission for an issue panel has at least one woman, would be a highly effective way to improve the gender balance of issue panels. ISPOR's own Women in HEOR Initiative states that "diversity in the field will result in better research and better healthcare decisions" [4]. We could not agree more.

Acknowledgements The authors wish to thank Koonal Shah for his helpful comments on the pre-print version of this paper, and Chris Sampson for his useful suggestion to publish a pre-print version of this paper. Finally, the authors are grateful to many comments and suggestions received through Twitter.

\section{Compliance with Ethical Standards}

Conflict of interest Jacoline Bouvy and Michelle Mujoomdar both report no conflicts of interest related to this article.

Funding No funding was received for the work reported in this paper.
Disclosure This work reflects the views of the authors only and cannot be understood as being made on behalf of, or reflecting the position of, any of the authors' employing organisations.

Open Access This article is distributed under the terms of the Creative Commons Attribution-NonCommercial 4.0 International License (http://creativecommons.org/licenses/by-nc/4.0/), which permits any noncommercial use, distribution, and reproduction in any medium, provided you give appropriate credit to the original author(s) and the source, provide a link to the Creative Commons license, and indicate if changes were made.

\section{References}

1. ISPOR 2019. Homepage. http://www.ispor.org/home. Accessed 8 Mar 2019.

2. BHE 2017. ICER versus NICE: the verdict from our ISPOR Glasgow issue panel. https://www.bhei.com/blog/icer-versus-niceispor-glasgow/. Accessed 8 Mar 2019.

3. ISPOR 2019. Issue panel submission information. https://www. ispor.org/conferences-education/conferences/submit-abstract/abstr act-submission-instructions/issue-panel-submission-information. Accessed 8 Mar 2019.

4. Karpowitz CF, Mendelberg T, Shaker L. Gender inequality in deliberative participation. Am Polit Sci Rev. 2012;106(3):533-47. https://doi.org/10.1017/S0003055412000329.

5. ISPOR 2019. Women in HEOR. https://www.ispor.org/strategicinitiatives/more/women-in-heor. Accessed 8 Mar 2019.

6. Morehoure C, Volkova A, Fierascu S. An end to manels: closing the gender gap at Europe's top policy events. Open Society Foundations; 2018. https://www.opensocietyfoundations.org/sites /default/files/an-end-to-manels-20180308.pdf. Accessed 8 Mar 2019.

7. Boring A. Gender biases in student evaluations of teaching. J Public Econ. 2017;145:27-41.

8. Mengel F, Sauerman J, Zulitz U. Gender bias in teaching evaluations. J Eur Econ Assoc. 2019;17(2):535-66.

9. Witteman HO, Hendricks M, Straus S, Tannenbaum C. Are gender gaps due to evaluations of the applicant or the science? A natural experiment at a national funding agency. Lancet. 2019;393:531-40.

10. Moss-Racusin CA, Dovidio JF, Brescoll VL, Graham MJ, Handelsman J. Science faculty's subtle gender biases favor male students. PNAS. 2012;109(41):16474-9. https://doi.org/10.1073/ pnas. 1211286109. 